\title{
Measure your team's performance, and publish the results
}

\author{
Fiona Godlee editor, BMJ
}

Clinical leadership in medicine can be hard to find, and good leadership even harder. One shining example in the UK in the past decade has been Bruce Keogh, now medical director of the NHS in England. As president of the Society of Cardiothoracic Surgeons in the aftermath of the Bristol paediatric cardiac surgery scandal, he persuaded his colleagues to make their mortality data publicly available. Since 2006 the raw data for individual cardiothoracic surgeons have been openly displayed online against an expected mortality range based on patient characteristics (http://heartsurgery.cqc.org.uk).

Admittedly, as Aniket Tavare explains (doi:10.1136/bmj.e4464), the society's hand was forced by a freedom of information request to hospital trusts in 2005. But things were already in train, and Keogh and colleagues delivered and have stood by their commitment to transparency.

What seemed remarkable at the time seems even more so now, because no other specialty has managed to do the same. The nephrologists get an honourable mention in Tavare's article, for publishing clinical outcomes for each renal centre, but this doesn't match the feat of the cardiothoracic surgeons.

Why should doctors measure and publicise their team's clinical performance? Because there is good evidence that it improves clinical outcomes, and because patients have a right to know where to find the best treatment and which teams to avoid. Despite some evidence that patients don't act on this kind of information, a recent initiative shows that they will if it's presented in the right way. Barnsley primary care trust assessed all its general practices against agreed best practice for 13 common conditions. Good performers got a green tick logo and the results were widely publicised. Between 5000 and 7000 patients changed practice as a result.

Tavare gives some of the reasons behind doctors' unwillingness to be measured. Not least are legitimate concerns about which measures to use and the quality of the data. But as Keogh said at the time, "[Technical] shortcomings are not important in the grand scheme of public disclosure."

There has been progress in the past six years. The Department of Health's information strategy has committed to publishing all outcomes data at clinical team level from national audits from April 2012. And from April 2013 the General Practice Extraction Service will join the Hospital Episode Statistics data, putting the UK in a globally unique position for evaluating outcomes across primary and secondary care.

But where is the clinical leadership pushing for public access to performance data of individual clinical teams? It hasn't come from the royal colleges. Perhaps, given the example of the cardiovascular surgeons, medical societies and associations are better equipped for this role. So where are they? Let's name a few in the hope of hearing from them: the British Thoracic Society, the British Cardiovascular Society, the British Association of Dermatologists, the British Society of Gastroenterology, the British Association of Urological Surgeons, the joint British Diabetes Societies, and the British Orthopaedic Association. What are you doing?

Cite this as: BMJ 2012;344:e4590

๑ BMJ Publishing Group Ltd 2012 